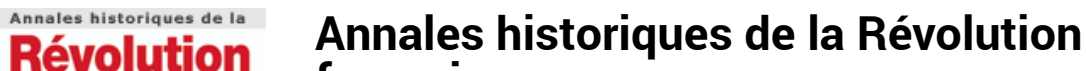

française française

344 | avril-juin 2006

La prise de parole publique des femmes

\section{Morris Slavin (1913-2006)}

James Friguglietti

\section{(2) OpenEdition \\ Journals}

Édition électronique

URL : https://journals.openedition.org/ahrf/6493

DOI : 10.4000/ahrf.6493

ISSN : 1952-403X

Éditeur :

Armand Colin, Société des études robespierristes

Édition imprimée

Date de publication : 1 juin 2006

Pagination : 217-218

ISSN : 0003-4436

\section{Référence électronique}

James Friguglietti, « Morris Slavin (1913-2006) », Annales historiques de la Révolution française [En ligne], 344 | avril-juin 2006, mis en ligne le 01 juin 2009, consulté le 23 avril 2022. URL : http:// journals.openedition.org/ahrf/6493 ; DOI : https://doi.org/10.4000/ahrf.6493

Ce document a été généré automatiquement le 23 avril 2022.

Tous droits réservés 


\title{
Morris Slavin (1913-2006)
}

\author{
James Friguglietti
}

\section{NOTE DE L'ÉDITEUR}

Traduction par Évelyne Martin-Gidel

1 Morris Slavin, qui est mort à Denver (Colorado) le 6 février 2006, à l'âge de quatrevingt-douze ans, a consacré toute sa carrière universitaire à l'étude de la Révolution française. Rien, pourtant, dans sa prime jeunesse, ne le prédestinait à devenir un éminent spécialiste dans ce domaine. Né à Kiev, en Russie, le 28 juin 1913, de parents qui étaient l'un et l'autre dentiste, il a connu les premières années de la Révolution russe. Après un séjour dans l'Allemagne de l'après-guerre, lui et sa famille ont émigré aux États-Unis en 1923, où ils se sont établis dans la ville industrielle de Youngstown (Ohio).

2 Désireux d'apprendre, le jeune Slavin commença sa scolarité dans les écoles publiques de la ville. Adolescent, il fut employé municipal, réparant les routes, balayant les rues et nettoyant les égouts. Il entra d'abord à l'Université de Youngstown avant de rejoindre en 1935 l'Université d'État de l'Ohio, où il se spécialisa en histoire et en anglais. Il obtint sa licence en 1938 à l'Institut d'Éducation, mais les emplois d'enseignants se faisant rares, Slavin travailla dans une aciérie locale, fort peu de temps car il en fut renvoyé à cause de ses activités syndicales. En 1941, il trouva un poste dans un lycée de Youngstown qu'il occupa durant vingt ans.

3 Après avoir servi dans l'armée américaine au cours de la Seconde guerre mondiale, il suivit des cours à temps partiel à l'Université de Pittsburgh, y obtenant sa maîtrise en 1952. Neuf ans plus tard, après de vastes recherches, il devint docteur ès Lettres à l'Université de Western Reserve, où il soutint sa thèse : Left of the Mountain: The Enragés and the French Revolution (Slavin était grandement influencé par La Révolution française de Mathiez, qu'il avait lu lorsqu'il était étudiant).

4 Slavin accepta un poste à l'Université d'État de Youngstown en 1961, où il devint professeur en 1972 et dont il prit sa retraite professeur émérite en 1981. C'est 
seulement à ce moment-là que, libéré de ses responsabilités universitaires, il s'occupa à écrire ses travaux majeurs.

5 Comme beaucoup de savants de sa génération, notamment George Rudé et Albert Soboul, il prôna une histoire vue d'en bas, privilégiant les couches populaires qui aidèrent à la chute de l'Ancien Régime et qui portèrent la revendication de réformes politiques, économiques et sociales radicales. Il étudia particulièrement les Enragés et les Hébertistes, qui furent au bout du compte violemment réprimés par les jacobins pendant la Terreur. Slavin publia dans des revues américaines une série d'articles sur Jacques Roux, Jean Varlet et Théophile Leclerc. Aux Annales historiques de la Révolution française, il offrit un article sur « L'épuration de prairial an III dans la section des Droits de l'Homme » (n² 232, avril-juin 1970). Avec «L'autre Enragé : Jean-François Varlet », il contribua au volume Eine Jury für Jacques Roux (1981), en hommage à l'historien allemand Walter Markov pour son soixante-dixième anniversaire.

6 Fondés sur une recherche minutieuse et bénéficiant d'une grande clarté de style, les livres de Slavin furent exclusivement consacrés aux classes populaires parisiennes et à leurs chefs: The French Revolution in Miniature: The Section Droits-de-l'Homme, 1789-1795 (1984) (compte rendu de Marc Bouloiseau dans les AHRF, $\mathrm{n}^{\circ}$ 261, juillet-septembre 1985); The Making of an Insurrection: Parisian Sections and the Gironde (1986) (compte rendu de Raymonde Monnier, AHRF, $\mathrm{n}^{\circ}$ 268, avril-juin 1987) et The Hébertistes to the Guillotine: Anatomy of a "Conspiracy» in Revolutionary France (1994). Slavin donna deux comptes rendus de lecture pour les AHRF, défendant ardemment la Révolution contre ses détracteurs: l'un du livre de Simon Schama, Citizens: A Chronicle of the French Revolution ( ${ }^{\circ}$ 277, juillet-septembre 1989), l'autre du livre de David McCullough, John Adams ( $\mathrm{n}^{\circ} 329$, juillet-septembre 2002).

7 Morris Slavin était un homme chaleureux, ouvert et convivial, un lecteur vorace qui trouvait cependant toujours le temps d'échanger ses idées avec ses nombreux amis. Après soixante années de mariage, il avait perdu sa femme, Sophie, en 2000, et laisse une fille, Jeanne, et deux petits-enfants. Pour ceux qui le connaissaient bien, il restera toujours un collègue attentionné et un merveilleux compagnon. C'était aussi l'un des plus anciens membres de la Société des études robespierristes et abonnés des AHRF, comme l'atteste la réponse qu'il a donnée à l'enquête récemment lancée par la Société auprès de ses adhérents. Membre de celle-ci depuis les années 1950, voici ce qu'il écrivait encore tout récemment sur les motivations de son adhésion: «La Société des études robespierristes représente l'étude et la défense d'un des événements les plus grands et positifs dans l'histoire du monde ». 